\title{
24h em Washington D.C.: a cobertura da CNN sobre o contexto político contemporâneo dos Estados Unidos ${ }^{1}$
}

André Luiz Marinho Costa

Pontifícia Universidade Católica do Rio de Janeiro - PUC-Rio

Departamento de Comunicação Social - Bacharelado em Jornalismo

\section{RESUMO}

O intuito deste trabalho é apresentar uma análise crítica da abordagem da CNN sobre a conjuntura política dos Estados Unidos, marcada por conflitos entre a imprensa e o presidente republicano Donald Trump. Para isso, através do modelo metodológico de análise de conteúdo, é realizada uma análise do programa Anderson Cooper $360^{\circ}$, exibido na CNN nos dias 22, 25, 26, 27 e 28 de maio de 2019. Espera-se, dessa forma, entender o conjunto de critérios jornalísticos por trás das decisões editoriais que guiam a cobertura do setor público norte-americano. Ao final, deve-se mostrar se tal cobertura pode ser considerada superficial, em comparação com outros meios, e as analogias que podem ser feitas em relação à cobertura esportiva.

\section{PALAVRAS-CHAVE}

Jornalismo; Política; Donald Trump; Televisão; Cobertura.

\section{Introdução}

Pioneira no conceito de notícias 24 horas por dia, a CNN promoveu transformações profundas na maneira como se exerce o jornalismo contemporâneo. Com alcance global inédito, o veículo mudou a forma como o setor político encara suas atribuições e diálogo com o público e, com isso, definiu a gramática jornalística do século XXI. Com a eleição do presidente americano Donald Trump, em 2016, assumiu protagonismo na cobertura política, principalmente após os ataques do republicano, que a acusa de parcialidade e classifica suas reportagens de fake news.

Em 2018, o canal chegou a processar a Casa Branca depois que a porta-voz Sarah Sanders revogou as credenciais do jornalista Jim Acosta, que havia feito perguntas consideradas inconvenientes a Trump. Uma das perguntas se referia à investigação do Conselho Especial,

\footnotetext{
${ }^{1}$ Artigo derivado de monografia de graduação em Jornalismo, orientada pela professora Bárbara Assumpção e apresentada em julho de 2019.
} 
liderado pelo procurador Robert Mueller, sobre a suposta interferência do governo russo nas eleições de 2016. Iniciado em 17 de maio de 2017, o inquérito terminou em 22 de março de 2019 e averiguou também se a campanha presidencial de Trump havia conspirado com os russos para influenciar o pleito em seu favor.

A fim de avaliar o estado atual da imprensa americana, o objetivo deste trabalho é analisar criticamente a cobertura do programa Anderson Cooper $360^{\circ}$, da CNN, sobre o episódio que marcou o fim da investigação. O intuito é, com isso, identificar os parâmetros jornalísticos que justificam ou não o estabelecimento do slogan da CNN "facts first" (fatos em primeiro lugar, em tradução livre), que indicaria a prevalência de conteúdos imparciais e objetivos, em detrimento de uma cobertura opinativa.

O método de pesquisa utilizado é a análise de conteúdo, pelo qual serão analisados os conteúdos veiculados nos programas exibidos nos dias 22, 25, 26, 27 e 28 de março de 2019, que são as datas subsequentes à divulgação da notícia da conclusão das apurações de Mueller. O trabalho consistirá em um exame de todo o material relativo à notícia da conclusão das investigações do Conselho Especial.

\section{Inimiga do povo?}

Quando na manhã de 16 de junho de 2015 o empresário Donald J. Trump desceu as escadas rolantes de seu edifício na luxuosa $5^{a}$ Avenida de Nova York, repórteres e amigos disputavam espaço no saguão para ouvir aquele esperado anúncio: o magnata finalmente decidira se lançar candidato à presidência dos Estados Unidos pelo Partido Republicano. A decisão encerrava décadas de especulações sobre as pretensões políticas do nova-iorquino, que emergira como figura conhecida do grande público no final dos anos 1970, catapultado pela frequente cobertura dos tablóides americanos sobre suas peripécias amorosas (BURNS, 2016).

\subsection{Improvável escalada à Casa Branca}

Com o lançamento do best-seller The Art Of The Deal, em 1988, Trump alcançou um outro patamar como celebridade. Na obra, ele compartilha algumas estratégias de negociações desenvolvidas durante sua ascensão pelo mercado imobiliário, que o tornaram bilionário. Escrita por um Ghostwriter, a publicação vendeu mais de 1 milhão de cópias e o ajudou a construir uma carreira como apresentador de televisão, à frente do programa The Apprentice 
(O Aprendiz), que estreou em 2004 na NBC. Só na primeira temporada, a atração atraiu uma média diária de 21 milhões de telespectadores (BRADLEY, 2017).

Apesar de todo esse histórico, a imprensa encarou os planos políticos do empresário com certo ceticismo. Ao noticiar o anúncio na Trump Tower, o jornal The New York Times classificou a candidatura como uma "jornada improvável". "Parece remoto prospecto de que republicanos (...) nomeariam [à disputa] um magnata do mercado imobiliário que já escreveu livros com títulos como Pense Como Um Bilionário, analisou a reportagem (BURNS, 2016).

O site Five Thirty Eight, especializado em realizar previsões sobre resultados de eleições, chegou a publicar uma reportagem intitulada "Por que Donald Trump não é um candidato sério". Nela, o jornalista Harry Enten (2015) argumenta que o projeto presidencial do empresário muito provavelmente seria frustrado por sua expressiva impopularidade. $\mathrm{Na}$ época, ele era rejeitado por cerca de $57 \%$ do eleitorado republicano.

Como afirmam Well et al. (2016), a imprensa foi pega de surpresa pelo rolo compressor do empresário, que resistia aos obstáculos e se impunha como fenômeno midiático. Na análise de Wells et. al. (2016), a capacidade de dominar a agenda da mídia levou Trump a superar os 16 outros concorrentes e despontar como o representante republicano nas eleições presidenciais de 2016 .

Diante do ceticismo geral quanto às chances do republicano, a mídia tradicional reagiu com espanto à notícia principal do dia 9 de novembro de 2016: Trump fora eleito o $45^{\circ}$ presidente dos Estados Unidos. O Washington Post classificou o resultado como "colossal". No The New York Times, o tom atônito foi semelhante: "Donald Trump foi eleito o $45^{\circ}$ presidente dos Estados Unidos na culminação de uma campanha explosiva, populista e polarizante que fez esforços implacáveis contra instituições e antigos ideais da democracia americana" (FLEGENHEIMER e BARBARO, 2016).

\subsection{Fatos versus fatos alternativos}

Na manhã congelante de 20 de janeiro de 2020, em frente a um público estimado de 600 mil pessoas (FROSTENSON, 2017), Donald Trump se posicionou diante do chefe da Suprema Corte americana, o juiz John Roberts. Com uma mão ao ar e outra sobre duas bíblias, seguradas pela mulher, Melania Trump, Trump jurou: "Eu prometo que fielmente vou executar o cargo de presidente dos Estados Unidos" (BAKER e SHEAR, 2017). Na televisão, as imagens indicavam que o gramado do capitólio, onde ocorria a cerimônia, estava cheio, 
mas não tão lotado quanto esteve nas duas posses do ex-presidente Barack Obama, em 2008 e em 2012.

No dia seguinte, o então porta-voz da Casa Branca, Sean Spicer, em seu pronunciamento diário à imprensa, foi categórico: "Esse foi o maior público que já assistiu a uma cerimônia de posse, ponto final". Spicer criticou a cobertura do evento e acusou a mídia de intencionalmente distorcer as fotos para minimizar o "enorme apoio" demonstrado ao presidente pela população (DAVIS e ROSENBERG, 2017).

Irritado, Trump ecoou comentários de seu assessor. Em um evento para agentes da CIA, o republicano disse que os jornalistas "são alguns dos seres humanos mais desonestos do planeta" e afirmou, sem apresentar provas, que cerca de 1,5 milhão de pessoas haviam comparecido à sua posse.

Ao programa Meet The Press, da MSNBC, a conselheira da Casa Branca, Kellyane Conway, tentou justificar os argumentos de Sean Spicer. Pressionada pelo apresentador Chuck Todd sobre as "mentiras" de Spicer, Conway cunhou um termo que ficaria marcado como simbólico da conjuntura política contemporânea. "Você está dizendo que são mentiras. Mas o Sean Spicer, nosso secretário de imprensa, apresentou fatos alternativos", afirmou, ao vivo, para surpresa do jornalista, que respondeu: "Fatos alternativos não são fatos. São mentiras" (MEET THE PRES).

A cadeia de eventos que ocasionou na gênese do termo "fatos alternativos" é representativa do contexto sociopolítico da segunda década do século XXI. Analisando as condições que levaram à saída do Reino Unido da União Europeia - o "Brexit" - e à eleição de Donald Trump, ambos em 2016, o jornalista britânico Matthew D'ancona (2018) identificou a emergência do que ele chama de "era da pós-verdade".

Segundo D'ancona, essa tendência é marcada pelo colapso da verdade como valor indispensável para a realização do exercício da política. No lugar disso, ganham relevância os "apelos à emoção e às crenças pessoais", conforme define o dicionário Oxford Dictionaries (D'ANCONA, 2018). Uma pesquisa conduzida pelo jornal The Washington Post indicou que, no primeiro ano de governo (2017), Trump formulou 2.140 alegações falsas ou enganosas uma média de 5,9 por dia.

Para a crítica literária Michiko Kakutani (2018), esses ataques frontais à verdade são apenas reflexos de uma tentativa de desmoralização das instituições democráticas e das normas vigentes. Os ataques corriqueiros à grande imprensa (mainstream media - MSM), portanto, 
surgem como esforços para apresentá-la como face desacreditada de uma ordem globalista que apenas beneficia a elite liberal (KAKUTANI, 2018). Como afirma D'ancona (2018), pouco importa para Trump se as assertivas que ele faz são realmente verdadeiras. "Não havia realidade estável e verificável, apenas uma batalha incessante para defini-la: seus "fatos" em contraste com os meus "fatos alternativos". O fundamental era se manter à frente nessa batalha", escreve o jornalista (D'ANCONA, 2018, p.25).

Conforme destaca D'ancona (2018), uma das características dos tempos atuais é fragilidade institucional, em que as ferramentas elementares para o fortalecimento da democracia perderam força de credibilidade. O jornalismo, argumenta o autor, tem a função de sustentar as bases das instituições democráticas, através da divulgação de notícias confiáveis. Como a confiança na mídia atingiu patamares ínfimos, a pós-verdade encontrou um ambiente fértil para florescer. "Não é por acaso que o presidente Trump tuíta rotineiramente que o New York Times está falhando", salienta D'ancona (2017, p.45).

Prova disso é que Trump já se descreveu em uma "guerra contra a imprensa" (ROSENBERG e DAVIS, 2017). Entre junho de 2015 e dezembro de 2017, o presidente publicou 990 tuítes hostis ao papel da mídia, de acordo com levantamento feito pela jornalista Stephanie Sugars (PETERS, 2016). Em 17 de fevereiro de 2017, poucas semanas após tomar posse, o republicano escreveu que a mídia é a "inimiga do povo", uma linha de ataque repetida diversas outras vezes (GRYNBAUM, 2017).

Poucos dias depois, em 25 de fevereiro, a Casa Branca negou o acesso a uma coletiva de imprensa a diversos veículos, entre eles os jornais New York Times, Daily Mail e The Guardian, os sites BuzzFeed e Politico e as emissoras de televisão BBC e CNN. (WEST, 2018).

O presidente não se furta a lançar ataques frontais não só contra veículos de imprensa, mas também contra jornalistas. Segundo a professora Sonja R. West (2018), especialista na Primeira Emenda da Constituição Americana, que garante a liberdade de expressão, Trump já chamou repórteres de "encrenqueiros", "injustos", "escórias", "nojentos", "desprezíveis", "desonestos", parciais", "lixos", "loucos", "doentes" e "entre alguns dos seres humanos mais desonestos do planeta" (WEST, 2018, p.915).

\section{3 "A CNN deveria ter vergonha"}

Donald Trump estava visivelmente irritado quando subiu ao púlpito para uma entrevista coletiva em 11 de janeiro de 2017. Poucos dias antes, a CNN havia noticiado a existência de um relatório que circulava entre as agências de inteligência norte-americanas com revelações 
degradantes sobre o então presidente eleito. Segundo o documento, que foi publicado na íntegra pelo site Buzzfeed, havia evidências de que o governo do presidente da Rússia, Vladimir Putin, estaria chantageando Trump com detalhes sobre uma suposta relação sexual que ele teria tido com uma prostituta russa alguns anos antes (BATISTA, 2017).

Questionado sobre a veracidade dos relatos, durante a entrevista, o republicano entrou em modo defensivo e criticou o Buzzfeed e a CNN. O repórter representante da emissora, Jim Acosta, então, reivindicou o direito por fazer uma pergunta, já que sua empresa estava sendo atacada. Trump, no entanto, não permitiu. "Eu não vou deixar você fazer uma pergunta porque você publica notícias falsas", disse, acrescentando que a "CNN" era uma "organização terrível" (BATISTA, 2017).

O episódio, ocorrido uma semana antes da posse do presidente, ilustra o relacionamento conturbado entre Trump e a CNN. Desde que emergiu como figura política de interesse nacional, Trump já chamou a emissora de "nojenta", "piada", "terrível", "total perda de tempo" e "lixo" (WEST, 2018).

As tensões entre o veículo e o presidente chegaram ao ápice em novembro de 2018 , quando a CNN decidiu processar a Casa Branca após seu repórter, Jim Acosta, ter tido as credenciais de acesso a uma coletiva de imprensa revogadas. O imbróglio começou no dia seguinte às eleições legislativas americanas, em que o partido do presidente, o Republicano, perdeu a maioria que detinha na Câmara dos Deputados. Naquele dia, Trump concedeu uma entrevista coletiva para falar dos resultados do pleito e também da caravana de imigrantes que, àquela altura, se aproximava da fronteira dos EUA com o México (LABORDE, 2018).

Questionado por Jim Acosta se a retórica adotada por ele não estaria demonizando imigrantes, Trump respondeu com fúria: "A CNN deveria ter vergonha de ter você trabalhando para eles. Você é uma pessoa rude e terrível", disse (LABORDE, 2018). Em seguida, Acosta tentou mudar de assunto, formulando uma pergunta sobre a investigação da suposta interferência da Rússia nas eleições americanas de 2016. No entanto, por seis vezes, o presidente repetiu que "já bastava" e tentou mudar o foco para outro repórter, enquanto uma assistente tentava tirar o microfone da mão de Acosta.

Mais tarde, pelo Twitter, coube à porta-voz da Casa Branca, Sarah Huckabee Sanders, anunciar a revogação das credenciais de Acosta, sob a alegação de que ele teria violado a assistente. Para embasar a medida, Sanders publicou um vídeo em que o repórter parece 
colocar as mãos sobre a estagiária. Contudo, poucas horas depois, diversos veículos de comunicação demonstraram que as imagens haviam sido distorcidas (AMATULLI, 2018).

Na semana seguinte, Acosta e a CNN entraram com uma ação contra Trump e cinco de seus assessores, incluindo Sanders. No processo, os denunciantes alegaram que a revogação das credenciais era uma clara violação da Primeira Emenda da Constituição americana, que trata da liberdade de imprensa (STELTER, 2018). Em 16 de novembro, uma liminar da Justiça obrigou a Casa Branca a permitir a entrada do repórter e, três dias depois, o governo decidiu restaurar as credenciais. Em resposta, a CNN retirou o processo (FARHI e FLYNN, 2018). Na avaliação de West (2018), esse tipo de ação demonstra que Trump emprega uma cruzada contra a Primeira Emenda.

\section{Estudo de caso: Anderson Cooper $360^{\circ}$}

"Dia histórico aqui em Washington", classificou o apresentador Anderson Cooper na abertura da edição de 22 de março de 2019 do programa Anderson Cooper 360 , da CNN. Na tarde daquela sexta-feira, o promotor Robert Mueller havia entregado ao Departamento de Justiça o relatório final sobre a investigação a respeito da interferência da Rússia nas eleições presidenciais de 2016, nos Estados Unidos.

O documento, fruto de quase dois anos de apuração, teria como objetivo apresentar esclarecimentos sobre um possível envolvimento da campanha de Donald Trump com os esforços disruptivos do governo do presidente russo Vladimir Putin. O arquivo também buscava entender se houve alguma tentativa de Trump, já como presidente, de suprimir as investigações, no que poderia ser interpretado como crime de obstrução de Justiça (LAFRANIERE e BENNER, 2019). Ao entregar o relatório ao procurador-geral, William P. Barr, Mueller sinalizava o fim do trabalho de sua equipe, o que explica o adjetivo "histórico" usado por Cooper.

O trabalho de Mueller seria entender se Trump, ou algum de seu emissário, teria conspirado com Vladimir Putin para derrotar a postulante democrata, Hillary Clinton. A questão emergira como possibilidade ainda durante a campanha, quando o empresário e seus aliados demonstravam incomum proximidade com o Kremlin. 
Ao longo dos 22 meses em que o trabalho do Conselho Especial esteve em andamento, Trump criticou a operação repetidas vezes e a classificou como "caça às bruxas Em boa parte das críticas, ele acusava a imprensa de fortalecer a investigação e de não cobrir o caso com imparcialidade.

Ao todo, 34 pessoas foram indiciadas por crimes diversos, dentre os quais seis faziam parte do círculo íntimo de Trump: os ex-assessores Roger Stone, Paul Manafort, George Papadopoulos, Rick Gates, Michel Flynn e Michael Cohen (TILLMAN, 2019).

A fim de entender os fatores que dirigem a construção jornalística da cobertura da imprensa, conforme proposto pelo presente trabalho, o item subsequente pretende examinar as cinco edições do programa Anderson Cooper $360^{\circ}$, da CNN, seguintes à notícia do fim da investigação conduzida por Robert Mueller. O programa é exibido de segunda a sexta-feira, entre $20 \mathrm{~h}$ e $21 \mathrm{~h}$ (horário de Nova York), e é apresentado pelo jornalista Anderson Cooper, que já realizou coberturas de eventos importantes e moderou debates presidenciais. A ideia é entender, a partir do estudo de caso, como, na prática, se exercem os conceitos formulados até aqui.

\subsection{Mueller entrega o relatório: como se portou o programa?}

$\mathrm{Na}$ abertura programa de sexta-feira (22/3) à noite, o primeiro após a entrega do relatório, Anderson Cooper classifica os episódios daquele dia como "boas notícias" para Trump. Em seguida, ele chama a repórter Pamela Brown, que destaca que uma de suas fontes considera os acontecimentos uma "vitória" para o governo.

Aos seis minutos, quando Jim Acosta entra ao vivo direto de Washington, ele abre o seu comentário salientando "comemorações" na Casa Branca: "Eu conversei com um assessor da campanha de Trump, mais cedo, e ele disse que este foi um grande dia para os Estados Unidos e 'nós vencemos'", relatou Acosta.

Mais tarde durante a atração, Cooper repete: "o ponto de partida, neste momento, é de boa notícia para o presidente Trump". Direto de Palm Beach, na Flórida, onde o republicano estava hospedado, o repórter Boris Sanchez entra ao vivo, em tela dividida com o apresentador, e ressalta a reação do círculo íntimo de Trump. "A reação privada tem sido de jubilação. Eles sentem como se isso fosse uma vergonha para os democratas e para a imprensa", conta. Ao utilizar termos frequentemente utilizados em disputas esportivas, os jornalistas comprovam a tese de C. Anthony Broh (1980), que afirma que a cobertura política possui similaridades semânticas com a de uma cobertura de cavalo. Conforme ressalta Broh, os 
acontecimentos são vistos sob a ótica de "perdedores" e "vencedores", sem devida atenção ao fato em si.

O sociólogo Pierre Bourdieu (1997) considera a televisão uma instância comunicativa que exerce uma "censura invisível", na medida em que o tema dominante é imposto, de forma arbitrária. Essa análise pode ser diretamente associada ao fato de que, com exceção dos cinco minutos finais, toda as duas horas do programa são dominados por um único tema. Não há espaço para outros assuntos e a investigação de Robert Mueller é encarada como a única questão importante daquele dia.

Conforme afirma Bourdieu (1997), os jornalistas fazem unilateralmente a seleção dos fatos a serem destacados de acordo com critérios ancorados na busca pelo sensacional e pelo espetacular. Isso explica por que, durante a transmissão, Cooper utiliza adjetivos grandiloquentes, como "histórico", e salienta que "a história está sendo construída naquele momento". "Com palavras comuns, não se faz 'cair o queixo do burguês', nem do povo. É preciso palavras extraordinárias", observa Bordieu (1997, p.26).

Ademais, a limitação de tempo restringe o discurso a um conteúdo raso, sem a possibilidade de aprofundamento (BORDIEU, 1997). Com isso, ao elevar discussões superficiais, deixa-se de atentar a informações importantes para que o cidadão construa sua participação no campo democrático. Tal superficialidade pode ser constatada pelo fato de que, durante o programa, não é exibida uma única reportagem, apenas análises de repórteres e de comentaristas.

Essa ausência de profundidade no discurso, de acordo com Cushion (2010), é consequência direta da emergência do modelo de notícias 24 horas por dia, que torna os prazos muito exíguos e dificulta a construção de matérias mais completas. Para Marilena Chauí (2006), os resultados dessa configuração são a deterioração da qualidade das notícias, que são apresentadas de forma mínima, rápida e, às vezes inexatas, e a inversão do papel do jornalismo, que passa a privilegiar seu caráter opinativo, em detrimento do investigativo.

A urgência por revelar fatos exclusivos, antes da concorrência, é uma constante que também pode ser observada durante o programa. Bourdieu (1997) explica que, no jornalismo, existe uma pressão cruzada, em que os profissionais são levados a correr atrás dos "furos" para evitar que o meio concorrente a obtenha primeiro. É por isso que, na entrada dos repórteres, eles sempre fazem questão de ressaltar que tiveram contato com pessoas próximas dos acontecimentos, repetindo frases como "minhas fontes me dizem". 
Na segunda-feira seguinte (25/3/2019), em que Anderson Cooper $360^{\circ}$ teve apenas 1 hora de exibição, a proporção dada ao tema foi menor. Àquela altura, o procurador-geral já havia divulgado o resumo das conclusões do relatório de Mueller e, portanto, mais informações já eram conhecidas. Naquela edição, o tema da investigação sobre a interferência russa também ganhou destaque, mas apareceu de forma mais modesta do que na sexta anterior. $\mathrm{O}$ assunto ocupou 27 minutos entre a uma hora de exibição do programa.

Destaca-se o comentário inicial de Cooper:

É uma boa notícia para o presidente que e ainda melhor para o país que o presidente dos Estados Unidos não conspirou criminalmente com um adversário internacional para ser eleito. Os democratas e aquelas que não gostam do presidente podem ficar decepcionados, mas, para o país, ter um presidente que não conspirou com um inimigo é boa notícia. (COOPER, 2019)

Note-se que todo o discurso está calcado em percepções subjetivas do jornalista, que não revela informação inédita. Conforme destaca Chauí (2006), o jornalismo televisivo tende a se inclinar para o viés interpretativo, em que os comentaristas sobrepõem a opinião pessoal aos fatos objetivos. No programa analisado, essa tendência reflete-se no fato de que, durante a transmissão, apenas dois repórteres - Jim Acosta e Manu Raju - entram na programação. Os outros participantes, que incluem analistas e políticos, têm a função de interpretar a notícia

Na edição do dia seguinte (26/3/2019), a proporção da pauta analisada dentro do programa foi ainda menor: cerca de 24 minutos. Na abertura, Anderson Cooper analisou um comentário de Donald Trump em que ele avalia o relatório do Mueller como positivo, embora, àquela altura, ele ainda não tivesse o lido. "Para ser generoso, o presidente nem sempre é preciso em sua linguagem, então considere que ele esteja confundindo [o relatório] com o resumo do Barr[...]. Mas, mesmo assim, ele está caracterizando o conluio de forma falsa", diz o apresentador.

Naquela edição, a primeira repórter só entra ao ar aos cerca de 20 minutos de transmissão. Maggie Habberman, correspondente do jornal The New York Times, por telefone, conta que Trump estava se sentindo vingado e que ele fez elogios ao procurador-geral - as primeiras informações novas veiculadas naquela noite.

A participação de uma profissional de outro veículo, aliás, demonstra o argumento de Bourdieu (1997) de que os produtos jornalísticos tendem a ser homogêneos, visto que a produção ocorre de forma coletiva. Isso porque, diz o autor, é hábito comum dos jornalistas 
consumirem diferentes meios de comunicação, a partir do qual constrói seus critérios de seleção do que deve ser noticiado.

Já na edição de quarta-feira (27/3/2019), as repercussões do relatório de Mueller ocuparam cerca de 10 minutos do programa. Nos minutos iniciais, o repórter Manu Raju entrou ao vivo para informar que, segundo sua fonte, William Barr não se comprometeria a divulgar a íntegra do relatório. Na sequência, Cooper entrevistou o ex-assessor de Trump, Steve Bannon, que apresentou suas visões sobre o caso.

A diminuição da presença do tema no noticiário reflete os critérios de agenda setting definidos pela imprensa. De acordo com esse conceito, a mídia tem o poder de decidir quais assuntos devem figurar no centro do debate público e quais devem ser ignorados (MESQUITA, 2008). Nesse sentido, na medida em que vai perdendo atualidade, a pauta também perde espaço dentro da cobertura midiática.

Na edição de quinta-feira (28/3), a última analisada pelo presente artigo, a investigação do Mueller voltou a ganhar espaço, ocupando todo o primeiro bloco do programa, de aproximadamente 18 minutos. Na ocasião, não houve entrada de repórteres, comprovando, mais uma vez, a tese de que o viés opinativo se sobrepõe ao objetivo.

\section{Considerações finais}

A partir da análise do programa Anderson Cooper $360^{\circ}$, da CNN, é possível observar um panorama geral do trabalho da imprensa americana em meio aos ataques proferidos pelo presidente Donald Trump. Não há indicações empíricas de que a postura hostil do republicano em relação à mídia esteja afetando a atuação dos jornalistas, mesmo diante do recrudescimento das tensões.

Na verdade, as transformações registradas na cobertura são anteriores à ascensão de Trump, conforme teorizado por vários especialistas, e estão relacionadas a movimentos intrínsecos ao jornalismo. Como evidenciado pelo objeto de estudo, os veículos têm priorizado o caráter interpretativo dos programas, em detrimento da tradicional objetividade que vinha sendo norma na imprensa desde o início do século XX. Na televisão, isso se reflete na diminuição do volume de reportagens exibidas e na presença mais reduzida de repórteres. 
Também permite-se destacar a gradativa perda de profundidade da cobertura jornalística, que apresenta informações de maneira cada vez mais rasa. Com a transição da era analógica para a digital, antigas concepções relativas ao tempo no jornalismo foram dando espaço a noções mais instantâneas. Isso encurtou prazos e tornou a transmissão de notícias em um exercício no qual a urgência se sobrepõe à acurácia e à qualidade. Prova disso é que o programa analisado é dominado por análises especulativas.

Um subproduto dessa realidade é a proximidade semântica entre a cobertura de política e de corridas de cavalo. Todos os fatos são vistos sob o prisma de perdedores e vencedores e, no lugar de priorizar questões concretas, como formulações de políticas públicas, há um foco desproporcional em rivalidades e disputas.

O estudo, embora apresente as conclusões delineadas acima, deixa aberto a possibilidade de diversos outros debates, como a pretensa imparcialidade dos produtos jornalísticos e o impacto das reportagens em resultados eleitorais.

\section{Referências bibliográficas}

AMATULLI, Jenna. People On Twitter Call For Sarah Huckabee Sanders To Resign For Jim Acosta Video. Huff Post, Nova York, 8 nov.2018. Disponível em:

https://www.huffpostbrasil.com/entry/people-call-for-sarah-huckabee-sanders-to-resignfor-jim-acosta-video_n_5be448e6e4b0dbe871a8109d. Acessado em 27/6/2019.

BAKER, Peter; SHEAR, Michael D. Donald Trump Is Sworn In as President, Capping His Swift Ascent. The New York Times, Washington, 20 jan. 2017. Disponível em:

https://www.nytimes.com/2017/01/20/us/politics/trump-inauguration-day.html Acessado em 27/6/2019

BORDIEU, Pierre. Sobre a televisão. Rio de Janeiro: Jorge Zahar, 1997.

BATISTA, Henrique Gomes. Ataques a CNN e Buzzfeed ilustram relação difícil de Trump com imprensa. O Globo, Washington, 12 jan. 2017. Disponível em:

https://oglobo.globo.com/mundo/ataques-cnn-buzzfeed-ilustram-relacao-dificil-de-trumpcom-imprensa-20761996 Acessado em 27/6/2019.

\section{$\mathrm{BROH}$, Anthony $\mathrm{C}$. Horse-race journalism: Reporting the polls in the 1976}

presidential election. Public Opinion Quarterly 44.4 (1980): 514-529.

BRADLEY, Laura. Donald Trump's All-Consuming Obsession with TV Ratings: A History.

Vanity Fair, Nova York, 20 jan. 2017. Disponível em:

https://www.vanityfair.com/hollywood/2017/01/donald-trump-ratings. Acessado em

27/6/2019. 
BURNS, Alexander. Donald Trump, Pushing Someone Rich, Offers Himself. The New York Times, Nova York, 16 jun.2015. Disponível em:

https://www.nytimes.com/2015/06/17/us/politics/donald-trump-runs-for-president-thistime-for-real-he-says.html. Acessado em 27/6/2019.

CHAUÍ, Marilena. Simulacro e poder: uma análise da mídia. São Paulo: Editora Perseu Abramo, 2006.

D'ANCONA, Matthew. Pós-verdade: a nova guerra contra os fatos em tempos de fake news. Barueri: Faro Editorial, 2018.

DAVIS, Julie, ROSENBERG, Matthew. With False Claims, Trump Attacks Media on Turnout and Intelligence Rift. The New York Times, Washington, 21 jan. 2017. Disponível em: https://www.nytimes.com/2017/01/21/us/politics/trump-white-house-briefinginauguration-crowd-size.html. Acessado em 27/6/2019.

ENTEN, Harry. Why Donald Trump Isn't A Real Candidate, In One Chart. FiveThirtyEight, Nova York, 16 jun. 2015. Disponível em: https://fivethirtyeight.com/features/why-donaldtrump-isnt-a-real-candidate-in-one-chart/. Acessado em 27/6/2019.

FLEGENHEIMER, Matt, BARBARO, Michael. Donald Trump Is Elected President in Stunning Repudiation of the Establishment. The New York Times, Nova York, 9 nov. 2016.

Disponível em: https://www.nytimes.com/2016/11/09/us/politics/hillary-clinton-donaldtrump-president.html. Acessado em 27/6/2019.

FARHI, Paul, FLYNN, Meagan. CNN drops suit against White House after Acosta's press pass is fully restored. The Washington Post, Washington, 19 nov. 2018. Disponível em; https://www.washingtonpost.com/lifestyle/style/cnn-drops-suit-against-white-house-afteracostas-press-pass-is-fully-restored/2018/11/19/519763fc-ec3a-11e8-8679-

934a2b33be52 story.html?utm term=.398a7fd480b6. Acessado em 27/6/2019.

FROSTENSON, Sarah. A crowd scientist says Trump's inauguration attendance was pretty average. Vox, Nova York, 24 jan.2017. Disponível em: https://www.vox.com/policy-andpolitics/2017/1/24/14354036/crowds-presidential-inaugurations-trump-average. Acessado em 27/6/2019.

GRYNBAUM, Michael M. Trump Calls the News Media the 'Enemy of the American People'. The New York Times, Nova York, 17 fev. 2017. Disponível em: https://www.nytimes.com/2017/02/17/business/trump-calls-the-news-media-the-enemyof-the-people.html. Acessado em 27/6/2019.

KAKUTANI, Michiko. A Morte da verdade: notas sobre a mentira na Era Trump. Rio de Janeiro: Editora Intrínseca, 2018.

KELLYANNE, Conway. Press Secretary Sean Spicer Gave 'Alternative Facts'. Meet the Press. NBC, 22 de janeiro de 2017. Programa de TV. 
LABORDE, Antonia. Trump a um jornalista da CNN na Casa Branca: "Você é uma pessoa grosseira e horrível". El País, Washington, 8 nov. 2018. Disponível em:

https://brasil.elpais.com/brasil/2018/11/07/internacional/1541616631 115445.html. Acessado em 27/6/2019.

MESQUITA, Nuno Coimbra. Televisão e política no Brasil: a Rede Globo e as

interpretações da audiência. São Paulo: Universidade de São Paulo, 2008.

PETERS, Jonathan. Trump Twitter spreadsheet tracks "a perpetual campaign against the press". CJR, Nova York, 21 dez.2017. Disponível em:

https://www.cjr.org/united states project/trump-twitter-spreadsheet-press-attacks.php. Acessado em 27/6/2019.

Special Counsel Mueller Ends Russian Probe. Anderson Cooper 360 ${ }^{\circ}$ CNN, 25 de março de 2019. Programa de TV.

Special Counsel Mueller Ends Russian Probe. Anderson Cooper $360^{\circ}$. CNN, 26 de março de 2019. Programa de TV.

Special Counsel Mueller Ends Russian Probe. Anderson Cooper $360^{\circ}$. CNN, 27 de março de 2019. Programa de TV.

Special Counsel Mueller Ends Russian Probe. Anderson Cooper $360^{\circ}$. CNN, 28 de março de 2019. Programa de TV.

STELTER, Brian. CNN sues President Trump and top White House aides for barring Jim Acosta. CNN, Nova York, 13 nov. 2018. Disponível em:

https://edition.cnn.com/2018/11/13/media/cnn-sues-trump/index.html. Acessado em 27/6/2019.

TILLMAN, Zoe. Here's Everyone Robert Mueller Charged. Buzzfeed News, Washington, 22 mar.2019. Disponível em: https://www.buzzfeednews.com/article/zoetillman/robertmueller-everyone-charged-russia-investigation. Acessado em 25/6/2019. WELLS, Chris et al. How Trump Drove Coverage to the Nomination: Hybrid Media Campaigning. Political Communication, Washington, vol. 33, p. 669-676, set./2016. WEST, Sonja. Presidential Attacks on the Press. Athens: University of Georgia, 2018. 